\title{
STUDY OF PSYCHIATRIC DISORDERS IN PATIENTS WITH PSORIASIS ATTENDING OUTPATIENT DEPARTMENT IN A TERTIARY HOSPITAL
}

\author{
Neelam Joshi, ${ }^{1}$ Pradip Man Singh, ${ }^{1}$ and Shristi Shrestha ${ }^{2}$
}

${ }^{1}$ Department of Psychiatry, ${ }^{2}$ Department of Dermatology, Nepal Medical College Teaching Hospital, Attarkhel, Gokarneshwor-8, Kathmandu, Nepal

\begin{abstract}
The neuro-immuno-cutaneous endocrine model explains the mind-body connection. This model explains how many inflammatory dermatoses are triggered or exacerbated by stress factors. These conditions are called psychophysiological skin diseases. Psoriasis is a common psychophysiological skin disease. It affects $2-4 \%$ of the population worldwide and involves multiple systems in the body. The rates of psychiatric comorbidities are high in psoriasis, but still, they are not given due attention which leads to an increase in morbidity and mortality in the long run. This study intends to uncover the psychiatric comorbidities in psoriasis patients. In this study, the prevalence of psychiatric disorders was investigated among 104 patients with psoriasis. Following rating scales were used; Hamilton rating scales for depression and anxiety, Presumptive stressful life event scale, Beck scale for suicidal ideation, and Dermatology life quality index. The prevalence of psychiatric disorders in Psoriasis patients was found to be $66.35 \%$. Among the psychiatric disorders, $29.8 \%$ were dependent on substances, $18.27 \%$ were found to be suffering from depression, $15.38 \%$ with anxiety disorder and $2.88 \%$ with psychotic disorders. Psoriasis has a high prevalence of psychiatric morbidity.
\end{abstract}

\section{KEYWORDS}

Psoriasis, Psychiatric Disorders, Stress, Quality of Life

\section{CORRESPONDING AUTHOR}

Dr. Neelam Joshi,

Lecturer

Department of Psychiatry,

Nepal Medical College Teaching Hospital,

Attarkhel, Gokarneshwor-8, Kathmandu, Nepal.

Email: neelum.joshi@gmail.com

Orcid No: https://orcid.org/0000-0002-0277-4849

DOI: https://doi.org/10.3126/nmcj.v23i2.38512 


\section{INTRODUCTION}

Psychodermatology or psychocutaneous medicine focuses on the relationship between psychiatry and dermatology, which deals with the study of the influence of psychosocial stress in the exacerbation and chronicity of skin illness. ${ }^{1}$ Both physical agents and psychosocial stress factors are linked with the natural history of several skin diseases, psoriasis being one of them.

Psoriasis is a chronic inflammatory autoimmune disorder that is associated with both genetic and environmental factors. It affects $2-4 \%$ of the population worldwide and involves multiple systems in the body. ${ }^{2}$

The etiopathogenesis of psoriasis-psychological stress relationship includes peripheral nervous system pathways, Hypothalamic Pituitary Adrenal (HPA) axis, Sympatheticadrenal-medullary (SAM) system, and immune mediated pathways. Most studies of the neuroendocrine response to stress in psoriasis have demonstrated a blunted HPA axis cortisol response and a heightened sympathetic response to a stressor. ${ }^{2}$ Stress is a trigger and an exacerbating factor in the pathogenesis of psoriasis. $^{3}$

In the last few decades, studies have pointed out the various mental disorders associated with psoriasis. ${ }^{4}$ Even though the rates of psychiatric comorbidities are high in patients with psoriasis, scant attention is paid to psychiatric comorbidities that affects the patients. ${ }^{5}$ Associated psychiatric comorbidity is likely to be caused by the complex interplay of stress, physical discomfort, and possible disfiguration inherent to psoriasis as well as an emotional response to the condition mediated by the patient's personality, emotional/cognitive state, and other social factors. ${ }^{6}$ Other contributory factors might be a heightened proinflammatory state associated with psoriasis as well as the patient's emotional reaction to the effects of psoriasis on the quality of life. ${ }^{2}$ If they are not taken care of, these comorbidities have a bearing on treatment improvement of primary dermatologic condition, including psoriasis as well. ${ }^{7}$

The main aim of this study was to evaluate the psychiatric disorders in patients with psoriasis. The relationship between stress and psoriasis, and the quality of life among psoriasis patients was also studied.

\section{MATERIALS AND METHODS}

This was a cross-sectional, descriptive study done in a tertiary care hospital of Kathmandu from April 14, 2019 to April 12, 2020. Ethical clearance was taken from the IRC of Nepal Medical College.

All diagnosed cases of psoriasis were included in the study. Those patients excluded were as follows:

1. Patients who refused to give consent

2. Past history of independent psychiatric illness

3. Very severe form of psoriasis (Pustular psoriasis, psoriatic arthritis)

4. Patients known to have other skin diseases before the onset of psoriasis

\section{Oral steroid use}

All patients diagnosed with psoriasis in the Dermatology department were referred to the Psychiatry department. Clinical (sociodemographic details) profile was recorded in a pretested proforma. Psychiatric diagnosis was determined by using ICD-10 DCR. ${ }^{8}$ Scales like Hamilton Rating Scale for Depression (HAM-D), ${ }^{9}$ Hamilton Anxiety Rating Scale (HAM-A), ${ }^{10}$ Dermatology Life Quality Index (DLQI), ${ }^{11}$ Beck Scale for Suicidal Ideation (BSSI), ${ }^{12}$ and PSLE $^{13}$ were applied to assess the respective domains. A total of 104 patients with psoriasis were included in the study. Data was entered in MS Excel. Statistical analysis was done by SPSS 16. T-test and Chi-square test were applied to determine the association, where p-value less than 0.05 was considered statistically significant.

\section{RESULTS}

This was a cross-sectional study where 104 patients with psoriasis were assessed for psychiatric disorders. The age of patients ranged from 5 years to 87 years with a mean of 40.91(SD+/- 14.76) years (Table 1$)$.

The prevalence of Psychiatric disorders in our study was $66.35 \%$. The commonest psychiatric diagnosis was substance dependence (29.8\%), followed by depression (18.3\%), anxiety disorders (15.4\%), and psychotic disorders (2.9\%). Among the patients diagnosed with psychiatric disorders; $10.6 \%$ reported suicidal ideations (Table 2).

In $59.6 \%$ of patients, stressful life events preceded the onset of psoriasis. Among them, $72.6 \%$ of the patients had an undesirable life event prior to psoriasis. In $37.5 \%$ of patients, psoriasis had a very large effect on the Quality Of Life (QOL), while in $20.2 \%$ of patients it had an extremely large effect on QOL (Table 3). 
Table 1: Distribution of respondents on the basis of socio-demographic variables $(n=104)$

Characteristics

1. Sex

2. Age

4. Marital status

5. Occupation

6. Religion

7. Address

8.SES

9. Family

10. Past Med hx

11. SI/SP

12. Self harm

13. Family h/o psy illness

14. Sleep problems

15. Course of illness

16. Attitude towards Illness

\section{Category}

Male

Female

$\leq 30$

31-40

41-50

51-60

$>60$

Illiterate

Under SLC

SLC

Intermediate

Bachelors

Masters

Single

Married

Widow

Separated

Retired

Unemployed

Labour

Semiskilled

Skilled

Hindu

Muslim

Buddhist

Inside KTM

Outside KTM

Low

Middle

Upper

Nuclear

Joint

present

absent

Yes

No

Yes

No

Yes

No

Yes

No

continuous

episodic

neutral

pessimistic

optimistic n (\%)

70 (67.30)

34 (32.69)

22 (21.10)

9 (37.50)

22 (21.25)

8 (7.69)

$13(12.50)$

32 (30.77)

13 (12.50)

18 (17.31)

14 (13.46)

18 (17.31)

9 (8.65)

12 (11.54)

89 (85.58)

2 (1.92)

1 (0.96)

2 (1.92)

19 (18.27)

8 (7.69)

41 (39.42)

34 (32.69)

83 (79.81)

2 (1.92)

19 (18.27)

38 (36.54)

66 (63.46)

46 (44.23)

56 (53.85)

2 (1.92)

37 (35.58)

67 (64.42)

61 (58.65)

43 (41.35)

10 (9.62)

94 (90.38)

5 (4.81)

99 (95.19)

16 (15.38)

88 (84.62)

40 (38.46)

64 (61.54)

37 (35.58)

67 (64.42)

27 (25.96)

21 (20.19)

56 (53.85)
Table 2: Distribution of respondents on the basis of ICD-10 DCR diagnosis

ICD-10 DIAGNOSTIC CRITERIA n (\%)

Mental and behavioral disorder due to psychoactive substance use:

Alcohol dependence

$14(13.46)$

Nicotine depndence

$16(15.38)$

Polysubstance dependence

$01(0.96)$

Total

$31(29.80)$

Schizophrenia, schizotypal and delusional disorders:

ATPD

$01(0.96)$

Psychosis NOS

02 (1.92)

Total

$03(2.88)$

Depressive episode:

Mild without somatic

symptoms

02 (1.92)

Mild with somatic symptoms

$01(0.96)$

Moderate without somatic

symptoms

$04(3.85)$

Moderate with somatic

symptoms

05 (4.81)

Severe without psychotic

symptoms

06 (5.77)

Severe with psychotic

symptoms

$01(0.96)$

Total

19 (18.27)

Neurotic stress related somatoform disorders:

Generalized Anxiety Disorder 01 (0.96)

Adjustment Disorder

04 (3.85)

OCD

$01(0.96)$

Social phobia

$01(0.96)$

Mixed depression anxiety

$01(0.96)$

Anxiety NOS

08 (7.69)

Total

$16(15.38)$

Total illness detected

$69(66.35)$

No illness detected

$35(33.65)$

Total number of patients 
The majority of patients with psoriasis diagnosed with psychiatric disorders were in the age group $31-40$ years $(33.3 \%)$ with a male preponderance $(71.0 \%)$. The male to female ratio was $2.06: 1$. The majority of them were married (85.5\%) and illiterate (34.8\%). Around $35.0 \%$ had skilled and semi-skilled jobs, whereas

Table 3: Distribution of respondents on the basis of Rating scales

Scales
HAM-D (n=104)

Normal

$82(78.85)$

Mild

7 (6.73.00)

Moderate

Severe

Very severe

Total

HAM-A (n=104)

Normal

$88(84.60)$

Mild

10 (9.60)

Mild to moderate

Moderate to severe

Total

104 (100)

BSSI(n=104)

Nil

93 (89.40)

Low intent

Medium intent

High intent

Total

104 (100)

DLQI (n=104)

No effect on pt's life

Mild effect on pt's life

Moderate effect on pt's life

Very large effect on pt's life

Extremely large effect on pt's life

Total

104 (100)

PSLES $(n=62)$

Desirable

Undesirable

Ambiguous

Total

$62(100)$
$75.4 \%$ of them were Hindu by religion. Half of the participants resided outside Kathmandu valley, $52.2 \%$ belonged to the middle class, and $58.0 \%$ had a joint family. Around $72.0 \%$ had a past medical history and $18.8 \%$ had a family history of psychiatric illness. One fourth of the patients having psychiatric illness reported suicidal ideations and 53.6\% reported sleep problems. Episodic illness was seen in $66.7 \%$ while $17.4 \%$ had a pessimistic attitude towards their illness. The psychiatric disorders had a statistically significant association with sleep problems and the age of the patient (Table 4).

In $27.5 \%$ of patients, psoriasis with the comorbid psychiatric disorder had an extremely large effect on QOL as compared to $20.2 \%$ of patients diagnosed only with psoriasis (Table 5).

\section{DISCUSSION}

A large number of studies have reported an increased prevalence of psychiatric morbidity in patients suffering from psoriasis. The mean age of the patients in our context was $40.91 \pm 14.76$ years.Seventy cases were male and 34 cases female patients. Females are less treatment seekers than males thus visit the hospital less frequently. This could be the reason that female enrollment was lesser in our study. This is similar to a study done by Sarkar et al. ${ }^{14}$

The prevalence of mental disorders in psoriasis varies worldwide. In our study, the prevalence of psychiatric disorders in psoriasis patients was $66.3 \%$. This resonates with the systematic review of the literature, where prevalence was in the range of $24-90 \%{ }^{15}$ Most studies worldwide report prevalence that falls within the above range. Similarly, Indian studies reported psychiatric morbidity ranging from 32.3-84.0\%. ${ }^{16}$ Other studies reporting similar results were Parafianowicz et $a l^{17}$ who noted point prevalence of $62.5 \%$ and Manjunath et $a l^{18}$ reporting $70.0 \%$ psoriasis patients with psychiatric comorbidity.

In our study, amongst the psychiatric disorders, substance dependence had the highest prevalence followed by depression and anxiety. In our study, $29.8 \%$ were diagnosed with substance dependence. Studies have provided an insight into substance related disorders in $24.8 \%$ patients with psoriasis, which is almost similar to our findings. ${ }^{15}$

Nicotine dependence was seen in $15.4 \%$ followed by alcohol dependence in $13.4 \%$ of patients and polysubstance dependence in 1.0\% in our study. Abedini et $a l^{19}$ reported nicotine 
Table 4: Relationship between psychiatric disorders according to ICD-10 DCR and different variables(n=69)

Socio-demographic variables ADS NDS Polysubst Dep Anxiety Psychosis n $\quad$ n

\begin{tabular}{|c|c|c|c|c|c|c|c|c|c|c|}
\hline \multirow{3}{*}{ Sex } & Male & 11 & 14 & 1 & 13 & 9 & 1 & 49 & 71.01 & \multirow{3}{*}{0.820} \\
\hline & Female & 3 & 2 & & 6 & 7 & 2 & 20 & 29.99 & \\
\hline & Total & 14 & 16 & 1 & 19 & 16 & 3 & 69 & 100 & \\
\hline \multirow{6}{*}{ Age* } & $=<30$ & 3 & 6 & 1 & 3 & 3 & - & 16 & 23.18 & \multirow{6}{*}{0.000} \\
\hline & $31-40$ & 7 & 4 & - & 4 & 6 & 2 & 23 & 33.33 & \\
\hline & $41-50$ & 2 & 2 & - & 5 & 4 & 1 & 14 & 20.29 & \\
\hline & $51-60$ & 1 & 2 & - & 2 & - & - & 5 & 7.2 & \\
\hline & $>60$ & 1 & 2 & - & 5 & 3 & - & 11 & 15.94 & \\
\hline & Total & 14 & 16 & 1 & 19 & 16 & 3 & 69 & 100 & \\
\hline \multirow{7}{*}{ Education } & Illiterate & 4 & 4 & & 9 & 6 & 1 & 24 & 34.78 & \multirow{7}{*}{0.183} \\
\hline & $<\mathrm{SLC}$ & 2 & 4 & & 2 & 1 & & 9 & 13.04 & \\
\hline & SLC & 6 & 5 & & 3 & 2 & & 16 & 23.19 & \\
\hline & XII & 1 & 1 & 1 & 1 & 3 & & 7 & 10.14 & \\
\hline & Bachelor & 1 & 2 & & 3 & 3 & & 9 & 13.04 & \\
\hline & Masters & & & & 1 & 1 & 2 & 4 & 5.80 & \\
\hline & Total & 14 & 16 & 1 & 19 & 16 & 3 & 69 & 100 & \\
\hline \multirow{5}{*}{$\begin{array}{l}\text { Marital } \\
\text { status }\end{array}$} & Single & 1 & 2 & 1 & 1 & 2 & 1 & 8 & 11.59 & \multirow{5}{*}{0.857} \\
\hline & Married & 13 & 14 & & 17 & 13 & 2 & 59 & 85.51 & \\
\hline & Widow & & & & & 1 & & 1 & 1.45 & \\
\hline & Separated & & & & 1 & & & 1 & 1.45 & \\
\hline & Total & 14 & 16 & 1 & 19 & 16 & 3 & 69 & 100 & \\
\hline \multirow{6}{*}{ Occupation } & Retired & 1 & & & 1 & & & 2 & 2.90 & \multirow{6}{*}{0.985} \\
\hline & unemploy & 2 & 3 & 1 & 2 & 5 & & 13 & 18.84 & \\
\hline & Labour & 1 & 2 & & 1 & 1 & 1 & 6 & 8.70 & \\
\hline & Semi skilled & 5 & 5 & & 9 & 5 & & 24 & 34.78 & \\
\hline & Skilled & 5 & 6 & & 6 & 5 & 2 & 24 & 34.78 & \\
\hline & Total & 14 & 16 & 1 & 19 & 16 & 3 & 69 & 100 & \\
\hline \multirow{4}{*}{ Religion } & Hindu & 10 & 13 & & 15 & 12 & 2 & 52 & 75.36 & \multirow{4}{*}{0.983} \\
\hline & Muslim & & & & 1 & & & 1 & 1.45 & \\
\hline & Buddhist & 4 & 3 & 1 & 3 & 4 & 1 & 16 & 23.19 & \\
\hline & Total & 14 & 16 & 1 & 19 & 16 & 3 & 69 & 100 & \\
\hline \multirow{3}{*}{ Address } & Inside KTM & 5 & 8 & & 8 & 10 & 3 & 34 & 49.28 & \multirow{3}{*}{0.646} \\
\hline & Outside KTM & 9 & 8 & 1 & 11 & 6 & & 35 & 50.72 & \\
\hline & Total & 14 & 16 & 1 & 19 & 16 & 3 & 69 & 100 & \\
\hline & low & 8 & 10 & & 6 & 7 & 1 & 32 & 46.38 & 0961 \\
\hline SES & middle & 6 & 6 & 1 & 13 & 9 & 1 & 36 & 52.17 & 0.961 \\
\hline & upper & & & & & & 1 & 1 & 1.45 & \\
\hline & Total & 14 & 16 & 1 & 19 & 16 & 3 & 69 & 100 & \\
\hline & Nuclear & 4 & 9 & & 9 & 6 & 1 & 29 & 42.03 & \\
\hline Family & Joint & 10 & 7 & 1 & 10 & 10 & 2 & 40 & 57.97 & 0.981 \\
\hline & Total & 14 & 16 & 1 & 19 & 16 & 3 & 69 & 100 & \\
\hline & present & 12 & 12 & & 15 & 10 & 1 & 50 & 72.46 & 0.765 \\
\hline Past & absent & 2 & 4 & 1 & 4 & 6 & 2 & 19 & 27.54 & \\
\hline Medical hx & Total & 14 & 16 & 1 & 19 & 16 & 3 & 69 & 100 & \\
\hline & present & 1 & 4 & & 9 & 2 & 1 & 17 & 24.64 & \\
\hline SI/SP & absent & 13 & 12 & 1 & 10 & 14 & 2 & 52 & 75.36 & 0.676 \\
\hline & Total & 14 & 16 & 1 & 19 & 16 & 3 & 69 & 100 & \\
\hline Family h/o & Yes & 2 & 1 & 1 & 6 & 3 & & 13 & 18.84 & \\
\hline raminy ito & No & 12 & 15 & & 13 & 13 & 3 & 56 & 81.16 & 0.634 \\
\hline Psy illness & Total & 14 & 16 & 1 & 19 & 16 & 3 & 69 & 100 & \\
\hline & Yes & 7 & & & 16 & 12 & 2 & 37 & 53.62 & \\
\hline Sleep * & No & 7 & 16 & 1 & 3 & 4 & 1 & 32 & 46.38 & 0.002 \\
\hline problem & Total & 14 & 16 & 1 & 19 & 16 & 3 & 69 & 100 & \\
\hline & continue & 4 & 6 & & 5 & 7 & 1 & 23 & 33.33 & \\
\hline Course of & episodic & 10 & 10 & 1 & 14 & 9 & 2 & 46 & 66.67 & 0.998 \\
\hline illness & Total & 14 & 16 & 1 & 19 & 16 & 3 & 69 & 100 & \\
\hline & Neutral & 9 & 7 & 1 & 5 & 3 & 2 & 27 & 39.13 & \\
\hline Attitude & pessimisti & & 3 & & 4 & 5 & & 12 & 17.39 & 0750 \\
\hline Attituae & optimistic & 5 & 6 & & 10 & 8 & 1 & 30 & 43.48 & 0.150 \\
\hline & Total & 14 & 16 & 1 & 19 & 16 & 3 & 69 & 100 & \\
\hline
\end{tabular}

${ }^{*} \mathrm{p}<0.05$ statistically significant 
Table 5: Relationship between psychiatric disorders according to ICD-10 DCR and DLQI

\begin{tabular}{|c|c|c|c|c|c|c|c|}
\hline DLQI & $\begin{array}{l}\text { Psychiatric } \\
\mathbf{d x}\end{array}$ & $\%$ & $\begin{array}{l}\text { No sychiatric } \\
\mathbf{d x}\end{array}$ & $\%$ & Total & $\%$ & p-value \\
\hline $\begin{array}{l}\text { No effect on pt's } \\
\text { life }\end{array}$ & 1 & 1.45 & 4 & 11.43 & 5 & 4.81 & \\
\hline $\begin{array}{l}\text { Mild effect on pt's } \\
\text { life }\end{array}$ & 12 & 17.39 & 3 & 8.57 & 25 & 14.42 & \\
\hline $\begin{array}{l}\text { Moderate effect on } \\
\text { pt's life }\end{array}$ & 15 & 21.74 & 9 & 25.71 & 24 & 23.08 & 0.144 \\
\hline $\begin{array}{l}\text { Very large effect on } \\
\text { pt's life }\end{array}$ & 22 & 31.88 & 17 & 48.57 & 39 & 37.50 & \\
\hline $\begin{array}{l}\text { Extremely large } \\
\text { effect on pt's life }\end{array}$ & 19 & 27.54 & 2 & 5.71 & 21 & 20.19 & \\
\hline Total & 69 & 100.00 & 35 & 100.00 & 104 & 100.00 & \\
\hline$\%$ & 66.35 & & 33.65 & & & & $* \mathrm{p}<.05$ \\
\hline
\end{tabular}

dependence in $19.2 \%$ of patients diagnosed with psoriasis, which is similar to our results. $41.0 \%$ patients reported to be smoking according Zink et $a l^{20}$ and $68 \%$ in a study by Pompili et al. ${ }^{21}$ The differences in results could be due to the different populations with different cultural practices.

Svanstrom et al reported $17-30 \%$ of patients with plaque psoriasis had alcohol use disorders. ${ }^{22}$ This is similar to a study reported by Mahajan et al. ${ }^{23}$ Other studies showed alcoholism in $12-18 \%$ psoriasis patient. ${ }^{6,24,25}$ Our study also reported similar findings.

Depression is also a common comorbid disorder with a prevalence of around 19-60\% in different studies. ${ }^{5,6,25-29}$ In our study, depression was reported in $18.3 \%$ of patients, which is similar to the above-mentioned study. In our study, mild depression was seen in $2.9 \%$ patients, moderate depression in $8.7 \%$, and severe depression in $6.7 \%$. Kumar et $a l,{ }^{26}$ in their study, identified $68.0 \%$ with mild, $18.0 \%$ with moderate, and $4.0 \%$ with severe depression. Disfigurement, stigmatization, high scores on pruritis, and pain are considered the contributory factors to depression.

Suicidal ideations are found in around 2-11\% patients, mostly in the context of depressed mood and anhedonia ${ }^{18,24,21,30}$ Similar finding was reported in our study where $10.6 \%$ reported suicidal intent, which was low in $6.7 \%$ and medium in $3.9 \%$ of patients. None of the patients reported high intent or suicidal attempts.
Psoriasis may lead to anxiety and vice versa. The prevalence of anxiety disorders in patients with psoriasis, based on the systematic review of studies, was found to range from 7 to $48.0 \%{ }^{31}$ Other studies also report a prevalence within this range. $6,7,17,18,26,32,33$ Anxiety disorders were identified in $15.4 \%$ in our study which is similar to the above findings.

Anxiety disorders have been reported in various studies where, adjustment disorders range from $15-62 \% .^{6,18}$ In our study, 3.8\% were diagnosed with adjustment disorders, which is similar to a study reported from Himachal Pradesh, ${ }^{34}$ where $2.4 \%$ of patients were diagnosed with adjustment disorders. Generalized Anxiety Disorder (GAD) was reported to be $9-13 \%$ in various studies. ${ }^{6,29}$ Kashyap et ${ }^{2}{ }^{34}$ reported $2.4 \%$ patients with GAD. Only $1.0 \%$ of cases of GAD were diagnosed in this study. Mixed anxiety depression was reported $13.7 \%$ by Biljan et al, ${ }^{6}$ which is diagnosed in $1.0 \%$ of patients in this study. Obssessive Compulsive Disorder (OCD) and Social phobia were seen in $1.0 \%$ each in this study. Social phobia was reported to be seen in $1.6 \%$ of patients by Kashyap et al. ${ }^{34}$ The difference in results could be due to the different populations under study, different methods of reporting used, or under-reporting of symptoms by the patients.

In this study, Anxiety NOS was reported in 7.7\% of patients; the highest among the different anxiety disorders. Amongst patients diagnosed with anxiety, $9.6 \%$ had mild, $4.8 \%$ mild to moderate, and $1.0 \%$ severe anxiety symptoms. 
Kumar et $a l^{26}$ reported $52.0 \%$ of patients with mild, $36.0 \%$ with mild to moderate, and $12.0 \%$ with moderate to severe anxiety.

Various studies have shown the evidence of a relationship between psychotic symptoms and psoriasis, which has been reported to range from 2-35\%. ${ }^{16,21-4}$ Similar to these studies, psychosis was diagnosed in $2.9 \%$ of patients in our study.

Sleep impairment in psoriasis could be due to pruritis, pain, or low mood..$^{35}$ A study by Gupta et $a l^{36}$ stated sleep disruption in $5.9-44.8 \%$ of patients. Findings resonate with our study, where $38.5 \%$ of patients had sleep problems

Psoriasis is a common psychophysiological skin disease with a major impact on patient's QOL. It was reported that patients with psoriasis suffer from similar deterioration in health related QOL as patients with cancer and CV disease. ${ }^{4}$ Seventy-nine percent of patients stated that psoriaisis had a negative impact on their QOL. ${ }^{25}$ In our study, 95.2\% of patients reported psoriasis affected their QOL. Among them, in $20.2 \%$ patients, psoriasis had an extremely large effect on patient's QOL, and in $37.5 \%$ of patients, a very large effect on QOL respectively. A study from Jammu, ${ }^{37}$ stated that $24.3 \%$ of patients with psoriasis had a very large effect on the QOL, and $4.0 \%$ had an extremely large effect on QOL.

Singh et $a l,{ }^{28}$ in their study, reported that the mean scores across each heading of DLQI and total were significantly more in the group with comorbid psychiatric disorders. In our study, in $27.5 \%$ of psoriasis patients with the comorbid psychiatric disorder had an extremely large effect on patient's life as compared to $20.2 \%$ patients diagnosed only with psoriasis, though the results are not statistically significant.

Patients with psoriasis have reported more stressful life events in comparison to control. Stressful life events are both a cause and aggravating factor for psoriasis. ${ }^{21}$ In $>50 \%$ patients, psychological stress exacerbates psoriasis. ${ }^{2}$ Very high rates of stressful life events (43-73.6\%) have been reported to be preceding the onset of illness in various studies. ${ }^{21,25,38,39}$ In our study, $59.6 \%$ of the patients reported stressful events before the onset of illness. Among them, $72.6 \%$ stated undesirable life events preceding the illness. A similar findings noted in another study ${ }^{21}$ in which $73.6 \%$ of patients had a negative life event 12 months before the onset of symptoms.

In Conclusion, this study showed that psoriasis patients have a high degree of psychiatric disorders. Therefore, psychiatric consultation of all psoriasis patients is highly recommended.

Limitations: Patients with pre-existing psychiatric disorders are also at a high risk of psoriasis, which couldn't be included here. This was only a cross sectional study, hence not representative of the population.

\section{ACKNOWLEDEMENT}

The authors would like to thank all the patients who volunteered for this study.

Source of Research Fund: None

Conflict of Interest: None

\section{REFERENCES}

1. Picardi A, Abeni D, Renzi C, Braga M, Melchi CF, Pasquini P. Treatment outcome and incidence of psychiatric disorder in dermatological out patients. J Eur Acad Dermatol Venereol 2003; 17: 155-9.

2. Gupta MA, Gupta AK. Treating psychiatric patients with psoriasis: clinical considerations. Psychiatric Times 2015; 32: https://www. psychiatrictimes.com/view/treating-psychiatricpatients-psoriasis-clinical-considerations.

3. Fortune DG, Main CJ, O'Sullivan TM, Griffiths CEM. Quality of life in patients with psoriasis: the contribution of clinical variables and psoriasis specific stress. Br J Dermatol 1997; 137: 755-60.

4. Ferreire BIR, Abreu JLD, Reis JP, Figueiredo AM. Psoriasis and associated psychiatric disorders: A Systematic review on etiopathogenesis and clinical correlation. J Clin Aesthet Dermatol 2016; 9: 36-43.

5. Carrascosa JM, Ballesca F. Psoriasis and psychiatric disorders: The next frontier. Actas Dermosifiligor 2017; 108: 502-5.

6. Biljan D, Laufer D, Filakovic P, Situm M, Brataljenovic T. Psoriasis, mental disorders and stress. Coll Antropol 2009; 33: 889-92.

7. Karia SB, Dsouza A, Shah N,Sonavane S, Bharati A. Psychiatric morbidity and QOL in skin disease: a comparison of alopecia aerate and Psoriasis. Industrial Psychiatr J 2015; 24: 125.

8. ICD 10 DCR Tenth Revision of International Classification of Diseases - Diagnostic Criteria for Research (ICD-10 DCR) WHO, 1992.

9. Hamilton M. A rating scale for depression. $J$ Neurol Neurosurg Psychiatr 1960; 23: 56-62.

10. Hamilton $M$. The assessment of anxiety states by rating. Br J Med Psychol 1959; 32: 50-5.

11. Finlay AY and Khan GK. Dermatology Life Quality Index (DLQI): a simple practical measure 
for routine clinical use. Clin Exp Dermatol 1994; 19: 210-6.

12. Beck AT, Kovacs M, Weissman A. Assessment of suicidal intention: the scale for suicidal ideation. J Consult Clin Psychol 1979; 47: 343-52.

13. Singh G, Kaur D, Kaur H. Presumptive stressful life events scale -a new stressful life events scale for use in India. Indian J Psychiatr 1984; 26: 107 14.

14. Sarkar S, Sarkar A, Saha R, Sarkar T. Psoriasis and psychiatric morbidity: a profile from a tertiary care centre of eastern India. J Fam Med Primary Care 2014; 3: 29-32.

15. Ferreira BR, Pio-Abreu JL, Reis JP, Figueiredo AM. Analysis of prevalence of mental disorders in psoriasis: the relevance of psychiatric assessment in dermatology. Psychiatra Danubina 2017; 29: 401-6.

16. Karia S, Dsousa A. Psychiatric aspects of psoriasis: a clinical review. Paripex Indian J Res 2015; 4: 4-5.

17. Parafianowicz K, Sicinska J, Moran A et al. Psychiatric comorbidities in psoriasis: pilot study. Psychiatr Pol 2010; 44: 119.

18. Manjunath M, Ramprasad KS, Prabhudev $\mathrm{MH}$, Vijaykumar S. Prevalence of anxiety and depression with psoriasis at tertiary care center. Sch J App Med Sci 2015; 3: 2001-3.

19. Abedini R, Lajevardi V, Nasimi M, Hallaji Z, Darvish M. Smoking, alcohol consumption and substance abuse in patients with psoriasis: a cross sectional study. Iranian J Dermatol 2019; 22: 92-6.

20. Zink A, Hermann M, Fischer T et al. Addiction: an underestimated problem in psoriasis healthcare. J Eur Acad Dermatol Venereol 2017; 31: 1308-15.

21. Pompili $\mathrm{M}$, Innamorati $\mathrm{M}$, Trovarelli $\mathrm{S}$ et al. Suicide risk and psychiatric comorbidity in patients with psoriasis. J Int'l Med Res 2016; 44: 61-6.

22. Svanstrom C, Lonne-Rahm S-B, Nordlid K. Psoriasis and alcohol. Psoriasis (Auckl) 2019; 9: 75-9. Published online 2019 Aug 21 doi:10.2147/ PTT.S164104.

23. Mahajan VK, Dhattarwal N, Chauhan PS et al. The association of alcohol use disorders and chronic plaque psoriasis: results of a pilot study. Indian Dermatol online J 2020. doi: 10.4103/idoj. IDOJ-226-20.

24. Jain N, Bukharia A, Khess CRJ, Munda SK. Psychiatric morbidity among patients with psoriasis and acne a comparative study. J Pakistan Assoc Dermatol 2016; 26: 337-46.

25. Rabin F, Bhuiyan SI, Islam T, Haque MA, Islam MA. Psychiatric and Psychological comorbidities in patients with psoriasis-a review. Mymensingh Med J 2012; 21: 780-6.

26. Kumar S, Kachhawha D, Koolwal GD, Gehlot S, Awasthi A. Psychiatric morbidity in Psoriasis patients: a pilot study. Indian J Dermatol Venereol Leprol 2011; 77: 625.

27. Lamb RC, Matcham F, Turner MA et al. Screening for anxiety and depression in people with psoriasis: a cross sectional study in a tertiary referral setting. Br J Dermatol 2017; 176: 102834.

28. Singh SM, Narang T, Dogra S, Verma AK, Gupta $S$, Handa S. An analysis of dermatological QOL scores in relation to psychiatric morbidities in psoriasis. Indian Dermatol Online J 2016; 7: 2089.

29. Padma K, Nanaware SS, Yadiyal A, Mathai PJ. Psychopathology in patients with psoriasis: a cross sectional clinical study. Int'l J Research Med Sci 2020; 8: 307-11.

30. El-Moselhy EA, Atlam SA, Mohammed AS, et al. Psychosocial Impact and Quality of Life among Adult Egyptian Patients with Psoriasis. Dermatol Case Rep 2015; 1: 1-9

31. Heming P, Bai JW, Pratt M, Sibbald C, Lynde C, Gulliver WP. The prevalence of anxiety in patients with psoriasis: a systematic review of observational studies and clinical trials. $J$ European Acad Dermatol Venereol 2017, 31: 798807

32. Tees S, Lim ZV, Theng CT, Chan KL, Giam YC. A prospective cross-sectional study of anxiety and depression in patients with psoriasis in Singapore. J European Acad Dermatol Venereol 2016; 30: 1159-64.

33. Tian Z, Huang Y, Yue $\mathrm{T}$ et al. A Chinese cross sectional study on depression and anxiety symptoms in patients with psoriasis vulgaris. Psychol Health Med 2019; 24: 269-80

34. Kashyap S, Kumar A, Kumar R, Shanker V. Psychiatric morbidity in psoriasis: a study in Himachal Pradesh, India. Int'l $J$ Research Med Sci 2016; 4: 2524-27. doi:http:// dx.doi. org/10.18203/2320-6012.ijrms 20161872

35. Satyanarayan Rao TS, Basaraj KH, Das K. Psychosomatic paradigms in psoriasis: psoriasis, stress and mental health. Indian J Pschiatr 2013; 53: $313-5$

36. Gupta MA, Simpson FC, Gupta AK. Psoriasis and sleep disorders: a systematic review. Sleep Med Rev 2016; 29: 63-75

37. Sakral S, Chowhan A, Sharma N, Dogra N, Dogra DR. A study of psychiatric morbidity and quality of life in patients attending a dermatological outpatient department at a tertiary care center in Jammu. Int'l J Current Research 2019; 11: 4947-51

38. Devrimci-Ozguven H, Kundakcin TN, Kumbasar $\mathrm{H}$, Boyvat A. The Depression, anxiety, life satisfaction and affective expression levels in psoriasis patients. J Eur Acad Dermatol Venereol 2000; 14: 267-71

39. Dika E, Maibach HI. Exogenous factors and psoriasis. Exog Dermatol 2004; 3: 214-22 